\title{
Chinese to English Lexical Transfer Errors in the Writing of Rural Senior High School Students
}

\author{
Zhenyan Ye \\ MATESOL, Faculty of Education, Hong Kong University, Hong Kong SAR, China
}

\begin{abstract}
The influence of first language (L1) has been widely recognized as a crucial factor in Second Language Acquisition (SLA). Language transfer is a typical phenomenon originating from this impact of L1. Many studies have tried to explore the influence of learners' L1 on their SLA. This paper reports a study conducted at a rural senior high school in eastern China. Based on the lexical transfer taxonomy proposed by Dodigovic et al (2015), this research attempted to at first identify examples of lexical transfer from Chinese to English caused by (1) Chinese polysemes, (2) Chinese collocations, and (3) multiword units (MWUs) yielded from learners writing. Subsequently, the patterns of and underlying reasons for lexical transfer were traced. 115 pieces of students writing were examined for error collection, and some typical examples from which were further analyzed to show how negative lexical transfer occurs. The results suggest that a great proportion of errors were caused by Chinese polysemes. The significant difference between the lexical specificity of Chinese and English as well as the word-for-word semantic equivalent assumption of $\mathrm{L} 2$ learners were found to be important reasons for negative lexical transfer. Pedagogical implications such adopting a wider range of semantization strategies and preventing learners from taking word-for-word relation between $\mathrm{L} 1$ and $\mathrm{L} 2 \mathrm{for}$ granted were drawn from the discussion.
\end{abstract}

Index Terms - lexical transfer, error, English writing, Chinese EFL learners, rural high school

\section{INTRODUCTION}

Second language acquisition (SLA) is a complex process influenced by a series of factors, among which learners' mother tongue, namely their first language (L1), can be a crucial one (Yule. 2014). Research has shown that learners' L1 can either facilitate or impede their SLA when they attempt to acquire the language with the help of the L1 (Gass \& Selinker, 1983). Specifically, when a linguistic feature between one's L1 and L2 happens to be the same, it will lead to correct understanding and use of the L2, while in the other case it will cause errors (Gass, 2013). This process is so-called "language transfer" as defined by Odlin (1989).

The occurrence of language transfer has been discovered at different linguistic levels, among which the transfer at lexical level is usually of great concern due to its role as the most basic unit in SLA (Schmitt, 2000). Many studies (Ellis, 2008; Jiang, 2000) have delved into transfer at lexical level and support the important role it plays in SLA. For example, Llach (2011) points out that the learning of L2 vocabulary is a process in which these words are linked to already established L1 schemas. That is to say, L2 learners depend heavily on their L1 while trying to understand words from L2. However, as is claimed by Elston-Guttler and Williams (2008), not only does the mapping between lexicons and concepts vary dramatically across languages, a large proportion of words in a language are polysemous (i.e. having more than one related meaning). Therefore, the dependence of L2 learners on their L1 in acquiring new words is rather unpromising and can lead to lexical errors.

The importance of using vocabulary accurately in language practice is always being highlighted. For example, Carter (1998) says that accurate use of vocabulary helps learners express their intended meaning appropriately while awkward lexical use can easily lead to confusion, which is less tolerable than any other types of mistake. However, as for second language learning in academic setting, a number of studies (e.g. Llach, 2011) have shown the difficulty of L2 learners in dealing with vocabulary due to lexical transfer is far more significant in terms of their productive skills than receptive skills. An important reason for this phenomenon is the direction of transfer: When using an L2 receptively, leaners are transferring the L2 to their L1, for which they have the language intuition and can thereby make an optimal choice; while this is not the case in the productive use of an L2, in which the direction of transfer is reversed. To improve the quality of L2 teaching and cope with lexical errors in learners L2 use, it is suggested that language teacher should pay attention to the origin and probable reasons for these errors.

Nevertheless, despite the importance of addressing lexical problems in SLA field, there are still few studies that examine lexical errors, especially for those which take the influence of L1 into account (Hemchua \& Schmitt, 2006). This status quo is even true in SLA field in China, where it is pointed out that SLA research focuses overwhelmingly on grammar and structure (Dai, 2005).

This situation, namely the lack of studies relevant to lexical errors in Chinese context, is the main reason that motivates the researcher of this current project to fill the gap and contribute to the understanding of L2 lexical errors caused by Chinese English learners. Following the taxonomy of lexical transfer proposed by Dodigovic et al (2015), the 
aim of this present research is to collect and analyze examples of lexical transfer errors from Chinese to English caused by (1) Chinese polysemes, (2) Chinese collocations, and (3) Chinese multiword units (MWU). In similar previous studies (Nesselhauf, 2005; Ma, 2015), learner corpus, which is defined as a set of authentic data comprised of learners' productive use of a language, is employed as the origin for example collection. In this current research, a learner corpus constituting 120 compositions by students in Rui'an No.4 High School, a rural senior high school in Zhejiang province of China, was examined. This present study is expected to address following research questions: (1) How do Chinese polysemes, Chinese collocation, and Chinese MWUs account for the impact of lexical transfer on Chinese English learners' use of English vocabulary? (2) What is the underlying reason that leads to the occurrence of negative lexical transfer from Chinese to English?

The paper is separated into six parts. In the second part, the theoretical foundations of this present research and some previous studies are reviewed. This is followed by the third part in which the learner corpus, data collection, and procedure of data analysis are described. The fourth part provides the results from data analysis and answers to research questions. Afterwards, the patterns of examples of lexical transfer collected in this study are discussed in detail in the fifth part. Finally, the sixth part concludes the research and talks about some possible pedagogical implications. Limitations and suggested future research direction are also included in this final part.

\section{LITERATURE REVIEW}

This part firstly conceptualizes key terms used in this study by presenting literature relevant to vocabulary and lexical transfer. Then, three categories of lexical transfer to be used as the framework for data collection in this present study are defined based on the taxonomy proposed by Dodigovic et al (2015).

\section{A. Lexicons and Transfer at Lexical Level}

\section{Studies on vocabulary in SLA}

The crucial role played by vocabulary in SLA has been increasingly recognized by researchers and linguists. For example, Nation (2001) claims that vocabulary is the most basic building block through which the language can be constructed and understood in other levels like sentences and texts. However, while the importance of vocabulary is being highlighted, more and more studies find the difficulty of L2 learners in learning L2 lexicons, which make them struggle with lexical errors (Schmitt, 2000).

The reason for this problem can be largely attributed to the nature of SLA. Different from first language acquisition in which the process is largely based on natural context of use (Clark, 2009), the process of SLA is usually more conscious and definition-dependent (Jiang, 2000). In this way, L2 words are weakly linked to concepts in L2 learners' mind, which drives them to seek L1 words to help with the understanding and use of L2 words. This is often referred to as the embodiment of subordinate bilingualism (Cook \& Singleton, 2014). This way of processing language in the production of L2 is said to be a major cause of lexical errors, which is also recognized as "transfer" (Gass \& Selinker, 1983).

\section{Lexical transfer}

Despite the existence of lexical transfer was recognized in various studies, there is still the divergence regarding the accurate definition of this term. Under this background, the working definition of "language transfer" proposed by Odlin (1989, p.27), which is highly acknowledged in the field of SLA, is cited here to serve as the foundation of transfer discussion in this present research:

Transfer is the influence resulting from the similarities and differences between the target language and any other language that has been previously (and perhaps imperfectly) acquired.

Based on this notion of transfer, there are two possible results if transfer occurs at lexical level: when the features of two lexicons from L1 and L2 are in line with each other, a positive transfer will be produced and leads to idiomatic use in L2; however, in opposite cases, negative transfer will happen and non-native like expression will be produced.

As was pointed out by Elston-Guttler and Williams (2008), the difference of lexical mapping among languages can be dramatic. Therefore, if L2 learners presuppose the consistency between an L1 and L2 lexical unit and transfer that L1 word to an L2 equivalent randomly, the probability of causing negative transfer will be high.

The process of producing negative lexical transfer can be essentially ascribed to the insufficient mastery of L2 lexicons. As was indicated by Jiang (2000), L2 learners depend heavily on definition of bilingual dictionary to understand a word. In this learning process, a new L2 word " $a$ " is simply treated as identical to a learnt L1 word " $b$ " in terms of their literal meaning. However, learning a word is far more than treating it as a container of its literal meaning. Rather, knowing a word means having the knowledge of the idiomatic way of using it, the context in which it usually appears, its possible function in an expression, and other words with which it is often related (Dodigovic, 2005). Influenced by these factors, the equivalent for a given L1 word in L2 can vary sharply, which renders the word-for-word transfer unpromising.

\section{B. The Taxonomy of Lexical Transfer}

In a recent study done by Dodigovic et al (2015), more than 300 pieces of dissertation written by Chinese students of tertiary level were collected. Through analyzing over 500 examples of negative lexical transfer yielded, it was found 
they can be best classified in terms of polyseme, collocation, and MWU. This taxonomy is adopted in this present study for data arrangement.

1. Transfer caused by L1 polysemes

According to Yule (2014), polysemy means one form (word) having two or more related meanings by extension. For example, "hand" can mean either "helper" or "performer" in different contexts, while they are related in terms of "people who do a specific work". This notion has to be distinguished from homonymy of which a word has two or more unrelated meaning (Yule, 2014), such as the "bank" as place for money and the "bank" as land along the side of a river.

Schmitt (2000) points out that the more basic and frequent a word is, the more likely it will be polysemous and has multiple semantically related meanings. Morimoto and Loewen (2007) even claim that most lexicons in a language tend to be polysemous. However, while polysemy is a common feature of word in most languages, it can be one of the most pronounced difficulties in learning an L2. In the framework of L1 polyseme transfer proposed by Elston-Guttler and Williams (2008), this difficulty is described as follows: given an L1 polyseme as " $X$ " which has two related senses as "a" and "b", yet "a" and "b" are expressed in L2 by two different lexicons "Y" and "Z" respectively, then how can L2 leaners decide between "Y" and " $Z$ " when they want to transfer "X"?

To avoid this dilemma, it is necessary to understand the knowledge of a word other than its literal meaning as was stated above (Dodigovic, 2005). In this way, leaners will be able to make correct decision among possible equivalents with the help of linguistic clues in context. However, this is usually rarely reached due to the insufficient mastery of L2 vocabulary in bilingual dictionary-based leaning (Jiang, 2000). When L2 learners do not have enough ability and knowledge to transfer an L1 word reliably, they tend to interpret new lexical units on the basis of their already acquired L2 through seeking word equivalent, which is usually referred to as "semantic equivalent hypothesis" (Ijaz, 1986). This process usually leads L2 learners to cause negative lexical transfer and treat their transfer as if take-for-granted.

2. Transfer caused by L1 collocations

The concept of "collocation" was first formally proposed and discussed by Firth (1957, cited in Nesselhauf, 2005), after which more and more importance has been attached to it in language learning. Lewis (1997, p.25) defines collocation as "the combination of words which occur naturally with greater than random frequency". It is generally agreed that collocation can be categorized into two basic types: semantic collocation and grammatical collocation (Nesselhauf, 2005). Whereas the former refers to phrases that consist of a dominant word (e.g. noun, adjective, verb) and a grammatical structure (e.g. preposition, infinitive) (Conzett, 2000), the latter is defined as those which are formed by two "equal words" that both contribute to the sense of the combination (Schmitt, 2000). This type of collocation can be subdivided into three types as adjective + noun, verb + noun, and noun + verb (Schmitt, 2000). Some typical examples of each category can be shown as follows:

TABLE I.

EXAMPLES OF COLLOCATIONS

\begin{tabular}{|l|l|}
\hline Grammatical collocation & Semantic collocation \\
\hline Adhere to & Strong evidence (adj. + n.) \\
\hline Familiar with & Pass exams (v. + n.) \\
\hline Work on & Rain falls (n. + v.) \\
\hline
\end{tabular}

Although the status of collocation is often emphasized in L2 teaching and learning (Conzett, 2000), its knowledge is quite difficult for learners (even those of high proficiency) to acquire (Schmitt, 2000).

A number of studies have revealed the impact of L1 on L2 collocation learning and use. In Biskup's (1990, cited in Nesselhauf, 2005) study, a group of Polish English learners were asked to translate collocations either from Polish to English or from English to Polish. As a result, they caused few errors in L2-L1 translation yet produced many in the other way.

In Chinese context, some research also shows similar results. For example, Lombard (1997) found that at least 1/4 of non-native like use of English collocation of Chinese English learners can be attributed to the transfer of their L1. In the research of Wang (2011), Chinese English learners' production of English v. + n. type collocation was analyzed through collocation test and it was found that nearly $62 \%$ of their production can be traced back to the transfer from expression in Chinese. In the study of Duan and Qin (2012), contextualized use of collocation (writing) rather than test was analyzed, through which some authentic examples of negative transfer of collocation like "eat (take) medicine" and "realize (achieve) increase".

A great number of previous studies on collocation utilize elicitation tests as the method, which has recently been criticized for being biased due to lack of data (Ma, 2015). Even for those which collected authentic data (e.g. Duan \& Qin, 2012), it can be found that most of them merely present the data without delving into the underlying reasons (Ma, 2015).

3. Transfer caused by L1 MWUs

Words tend to link and form clusters systematically (Sinclair, 1991). Except for collocational connection of words as discussed above, sometimes words may combine together as clusters that comprise more than only collocational ties. As the language develops, some word clusters were settled down and usually used by people as set phrases. This string of lexical units is defined by scholars as multiword units (Schmitt, 2000). Based on previous research, this category can also be subdivided into four types as: idioms, proverbs, fixed phrases, and phrasal verbs (Moon, 1998; Schmitt, 2000). 
The importance of MWUs in SLA has been highlighted by many researchers. For example, Biber (2009) argues for its crucial role by claiming that MWUs are stored in long-term memory and can be easily activated and thereby contribute to the efficiency of language production. This significant role enjoyed by MWUs drives many scholars (e.g. Chen \& Baker, 2010; Ädel \& Erman, 2012) to research how MWUs are used by L2 learners and results suggest that L2 learners use MWUs less frequently then native speakers in general yet they tend to overuse some specific MWUs.

There is lack of studies that focus on the influence of L1 on L2 MWUs acquisition (Ma, 2015). Paquot (2013) collected English writing done by French learners and examined their use of English MWUs with 3-word sequences. It is found that most of their use can be traced back to French as L1 transfer and many errors were caused when the equivalent of L1 MWUs does not exist in English. This research merely analyzed MWUs of 3-word sequences without exploring the reasons for transfer.

Chen and Baker (2010) compared English academic writing done by native speakers and L2 leaners. They counted some frequently used MWUs in these writing and found that native speakers use a far wider range of MWUs than L2 learners. Moreover, it was also discovered that there is dramatic difference between certain MWUs that are frequently used by native speakers and L2 learners. However, this research did not discuss the reason for these results.

\section{METHODOLOGY}

\section{A. The Learner Corpus}

This present research is a corpus-based one which pre-defines Dodigovic et al's (2015) taxonomy of Chinese to English lexical transfer as the framework. While there were 120 pieces of student writing collected, five pieces among them were discarded due to illegibility. The learner corpus utilized in this current study is comprised of 115 pieces of writing (16,758 English words in total, by 60 year three students at Rui'an No.4 Senior High School). Rui'an No.4 Senior High School is a rural senior high school of provincial key status of second class.

There are mainly two reasons for choosing the writing by this group of students. Firstly, the English proficiency of rural senior high school students is more representative of the average level of Chinese senior high school students. Data has shown that the proportion of rural senior high school in mainland China can be over 60\% (Shi, 2012). Due to the uneven distribution of education resources in China, there is a conspicuous gap between the English teaching quality and students' English level of rural senior high school and urban senior high school, while their English performance was rarely concerned in previous studies. Therefore, choosing this rural senior high school as the site for data collection may provide an insight into the English use of this important student group in China. Moreover, year 3 is the final year in Chinese senior high school, which means at this stage these students have already been taught all required knowledge of grammar and vocabulary needed to be mastered at senior high school level. In other words, they are able to fully represent supposed English proficiency of a senior high school student in terms of taught knowledge.

All students whose writing was collected for the learner corpus in this present research are native speakers of Chinese. They were aged 17-18 and have been learning English for at least 5 years. In the research done by Shi (2012), 800 students from 10 rural senior high schools in eastern China were assessed in terms of their English proficiency based on Common European Framework of Reference for Languages. The results show that while 483 students ranked A2, 317 students were judged to be B1. Given the class of this school (rural high school of second class provincial key), it is fair to assume their proficiency as around lower-intermediate.

The writing collected for this current study is varied in terms of genre and topic. The major types of the wring include letter, narrative prose, fairy tale, and argumentative essay. The main reason for collecting writing based on a variety of topics is to elicit students' use of vocabulary as diversely as possible, which will provide a more comprehensive insight into their actual L2 knowledge and lexical transfer pattern. It is also worth mentioning that the writing collected is done in regular simulation tests conducted to prepare students for upcoming university entrance examination so that the data is authentic and involves minimal risk.

\section{B. Procedure}

After the learner corpus was built, the data is ready for processing. Based on the taxonomy of Chinese lexical transfer as proposed by Dodigovic et al (2015), the researcher read through students' writing carefully, attempting to identify lexical errors that are possibly caused by L1 lexical transfer and record them tentatively in an Excel file.

Since the researcher of this present study is also an L2 learner of English who may not be able to judge the appropriateness of English production originating from transfer, two assistive tools, namely Youdao machine translation engine and Corpus Concordance English, were employed in the procedure. Developed by Netease, Youdao Translation is an application based on search engine and Internet corpus. This application is able to provide a considerable number of authentic examples of English translation from Chinese in context. This function is useful in helping the researcher decide which possible equivalents in English is the best one for a given Chinese polysemous word. Corpus Concordance English, available from http://www.lextutor.ca, is a webpage-based program built on the corpus of Brown, BNC Written, and Spoken. This program can be used to check how frequently proper collocation patterns appear in authentic English, through which the researcher is able to judge if a certain transfer of collocation is appropriate.

In this current research, every lexical error produced as an English word, collocation, and an MWU was regarded as a single example of negative transfer. All examples recorded tentatively at the first stage were checked with the assistance 
of Youdao Translation and Corpus Concordance English and some examples were deleted if they pertain to positive transfer or non-transfer error. Subsequently, instances of typical Chinese negative lexical transfer were arranged in an Excel file according to three categories (polyseme, collocation, and MWU) as defined by Dodigovic et al (2015). Apart from the category, the Chinese pinyin, Chinese equivalent, correct English, and the context of each example were indicated in the file (see appendix for the list of all examples of negative lexical transfer from Chinese).

Error frequency of examples from each category is also calculated to see if negative lexical transfer is a significant error type in the writing of target students. In order to render the data comparable to previous studies, the raw frequency was normed to a basis of 1,000 words according to the formula suggested by Biber, Conrad and Reppen (1998):

Error frequency $=($ total error number/total word count $) * 1,000$

\section{RESUlTS}

Graphs illustrating major statistical results and finding drawn from data analysis in this current research are presented in this part. There are totally 101 typical examples of negative lexical transfer identified in the learner corpus incorporating 115 pieces of student writing. With regard to the first research question: How do Chinese polysemes, Chinese collocation, and Chinese MWUs account for the impact of lexical transfer on Chinese English learners' use of English vocabulary? The number of lexical errors stemming from the three pre-defined types of Chinese transfer was calculated.

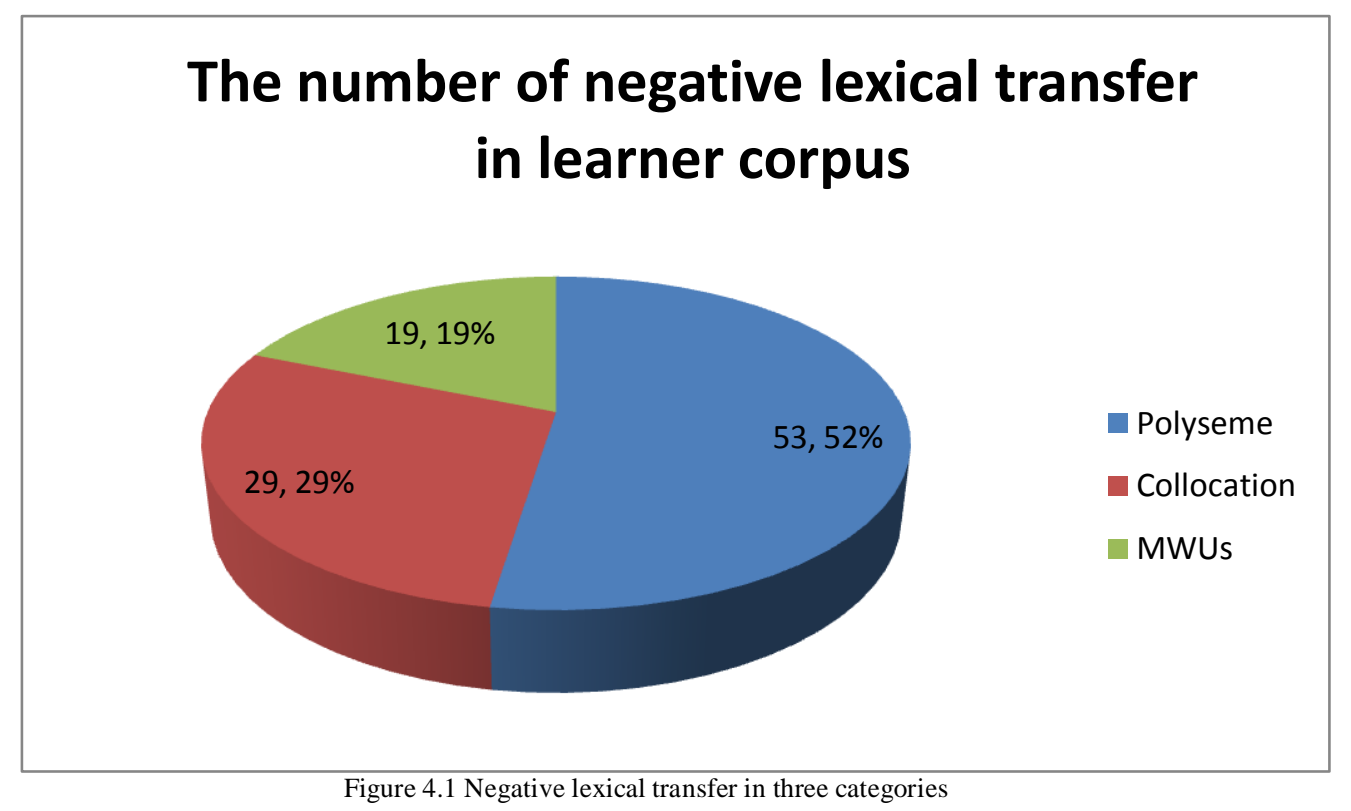

Figure 4.1 indicates the number and proportion of lexical errors caused by transfer from Chinese polysemes, Chinese collocations, and Chinese MWUs respectively. It can be seen that Chinese polysemes are responsible for the greatest number of lexical errors caused in learner corpus, which constitute over half of the total number. This is followed by Chinese collocations and Chinese MWUs, which account for $29 \%$ and $19 \%$ of the total number respectively.

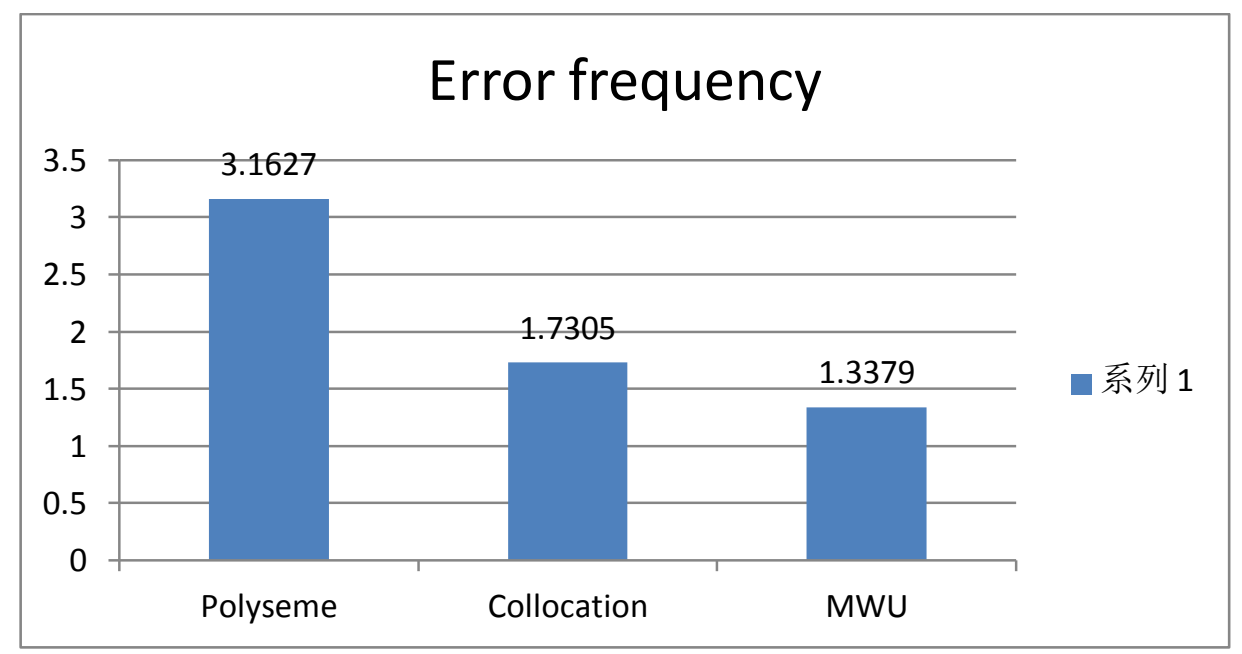

Figure 4.2 Error frequency of each category on a 1,000 words basis 
Figure 4.2 shows the error frequency of each category on a 1,000 words basis. Be more specific, in writing done by target students, $3.1627,1.7305$, and 1.3378 error can be attributed to Chinese polysemes, Chinese collocations, and Chinese MWUs respectively in every 1,000 words language unit.

\section{DISCUSSION}

Through considering previous studies that reach similar or different conclusions, this section firstly tries to critically interpret statistics and findings obtained from this current research. Afterwards, some typical examples from each category of Chinese transfer are analyzed in terms of their pattern, based on which possible underlying reasons of L2 learners' transfer are discussed.

\section{A. Interpretation of the Results}

The statistical results emerging from this present study suggest that the most transfer errors are caused by Chinese polysemes, which are followed by Chinese collocations and Chinese MWUs. This significant impact of polysemous words on Chinese English learners' transfer is consistent with the findings in some recent studies (Cheng, 2013; Ma, 2015). In the research of Cheng (2013), a group of Chinese English learners of higher-intermediate proficiency were asked to translate several Chinese words and lexical bundles into English in context. As a result, the highest error rate was found in participants' transfer of single Chinese polysemous words. In the study of Ma (2015), 50 pieces of dissertation written by advanced Chinese English learners ( $\mathrm{C} 1$ level) were analyzed in terms of negative transfer. Among 395 identified lexical transfer errors, those caused by Chinese polysemes are found to account for $50 \%$ of the total number. IThis consistency of results may indicate that polysemous words are the lexical category which poses greatest difficulty on Chinese English learners, regardless of their current L2 proficiency level. This conclusion can be further validated and polished by comparing the error frequency of three categories in these two studies.

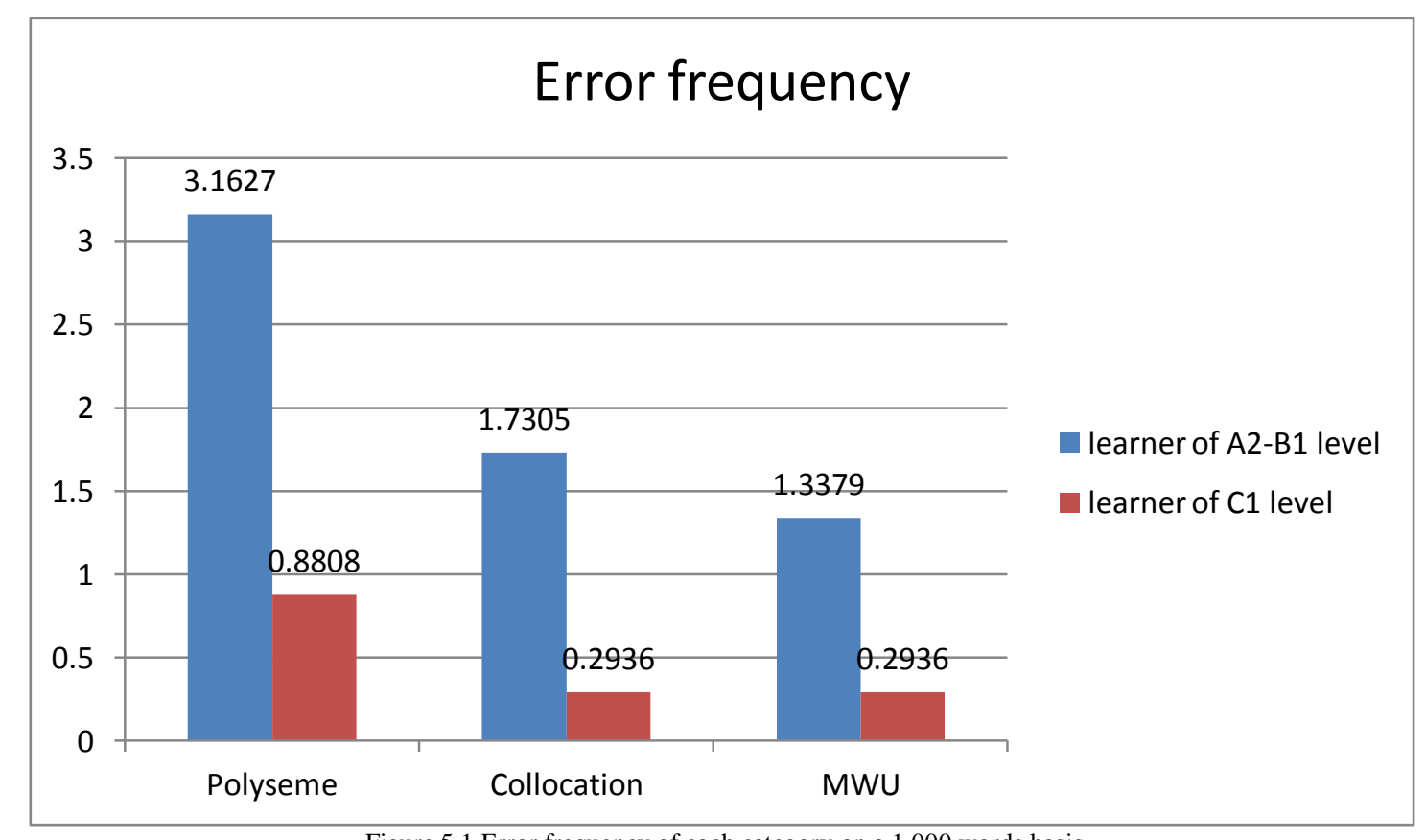

Figure 5.1 Error frequency of each category on a 1,000 words basis

Figure 5.1 indicates that lexical errors caused by Chinese polysemes are most significant in both two groups of learners, though the increase of proficiency leads to the decline of error frequency in each category respectively.

This conspicuous influence of Chinese polysemes can be partly explained by the uniqueness of Chinese lexical system. Many studies (e.g. McBride-Chang et al, 2006; Huang, et al, 2010) have pointed out that Chinese can be one of the most economical languages in terms of vocabulary. Specifically, while English distributes different meanings to several separate words, Chinese uses the same word (character) to do so (Duan and Qin, 2012). However, this makes the word specificity between Chinese and English rather asymmetric; in other words, learners are likely to face several possible equivalents when transferring a Chinese polyseme into English. This feature of Chinese vocabulary makes polysemes a quite difficult category for Chinese English learners to cope with in language transfer.

\section{B. Negative Lexical Transfer Caused by Chinese Polysemes}

In order to gain a deeper insight into Chinese to English negative lexical transfer, typical examples identified in the research are discussed here in detail. As was shown in the Results part, the lexical errors stemming from Chinese polysemes are of greatest proportion (52\%) among three categories. It was also revealed that this result can be partly ascribed to the dramatic difference between the lexical specificity between English and Chinese. Two typical examples 
are presented as follows (the words being negative transferred are underlined; possible correction is marked by “*”; grammatical error is not corrected):

1. 那个周末你可以住我家

You can live in my home at that weekend.

*You can stay at my home at that weekend.

The Chinese word “住” (zhu) is polysemous and can be transferred to English by at least two lexical forms: "live" and "stay". Through checking Youdao Translation, it can be found that these two words have different usage, albeit both of them can refer to "someone being in somewhere". For "live", it is usually used to talk about a place where a person's home or residence is located. This notion implies a place for relatively long period of living. However, the use of "stay" often suggests a place for temporary living, such as a hotel for stay during a journey. In the example sentence shown above, it is clear that a place for short-term (a weekend) living is being mentioned, and therefore "stay" should be the correct equivalent for “住” here.

2. 我找到了一个银行并把硬币兑换成了现金。

I found a bank and changed some coins into cash.

*I found a bank and exchanged some coins for cash.

While the pattern of most examples caused by Chinese polysemes as found in the study is similar to Example 1 above (i.e. the inability of choosing correctly among possible equivalents), there are a few special cases like example 2 that worth analyzing. This type of example is special because students produce a word that does not pertain to any possible equivalent of the source language. Specifically, in this case, "change" cannot be found as the literal translation of “兄换” (dui huan) in Chinese-English bilingual dictionary. This type of transfer can be explained by the case pointed out by Jiang (2000), where L2 learners have to transfer a new word which has not even been learnt through definition on bilingual dictionary. In this way, they will still attempt to achieve the transfer by searching a learnt word of similar meaning based on either Chinese character ("换” in this case) of the word.

\section{Negative Lexical Transfer Caused by Chinese Collocations}

Lexical errors caused by Chinese collocations were found to account for $29 \%$ of the total number. At first, a typical example of grammatical collocation is discussed as follows:

1. 然而在另一方面, 这可能造成危险

In the other hand, this may cause danger.

* On the other hand, this may cause danger.

In this example, the Chinese words “在” and “另一方面” are being collocated. It is clear that this student randomly selects a preposition "in" for the word “在”, without noticing that there is a set phrase (i.e. on the other hand) in English for this meaning

Subsequently, examples that belong to each subcategory of lexical collocation are discussed.

2. 为了解决焦虑, 老师应当做到以下几点。(v.+n.)

To solve anxiety, teachers should do these.

*To cope with anxiety, teachers should do these.

3. 看! 天已经黑了。(adj. + n.)

Look! The sky is already black.

*Look! The sky is already dark.

4. 这里有很多有趣的标志建筑。(n. + n.)

This place is full of interesting sign constructions.

*This place is full of interesting landmarks.

It is clear that students were influenced by Chinese collocation in producing these English phrases. In example 2, while "solve" is a possible equivalent for the Chinese word “解决”, it is usually collocated with words like "problem" and "puzzle" but not "anxiety" in English. Another English equivalent "cope with" is more appropriate in this context. From this example, it can be seen that the problem essentially pertains to polyseme transfer, as the student failed to choose a correct equivalent for the Chinese polyseme “解决”. In example 3, while "black" is a possible choice for Chinese word "黑", it is not used to collocate with "sky". The reason for this negative transfer is because in Chinese people usually say “天黑了” (sky is black), which is assumed to be the same in English by the student in this case. In example 4, the whole phrase is unlinked by the student into “标志性” and “建筑” and then transferred literally into "sign" and "construction" respectively. Nevertheless, this sense is able to be expressed in English with only a single word "landmark".

These examples support the findings of Yamashita and Jiang (2010), in which it was discovered that L2 learners produce more negative transfer when L1 and L2 collocations are not congruent. That is to say, since L2 learners tend to assume the word-for-word equivalent between L1 and L2, they are likely to cause transfer errors when this mechanism is not applicable in collocation transfer.

D. Negative Lexical Transfer Caused by Chinese MWUs 
Negative lexical transfer caused by Chinese MWUs was found to account for $19 \%$ of total errors in this current research. Two typical examples of this category are discussed as follows:

1. 妈妈, 我没事。

Mom, I have no matter.

*Mom, I'm OK.

This sentence is written in a scene of a narrative where a boy replies to his mother when asked if he is traumatized by the loss of money. In this context, if the boy is OK, answers like "I'm OK" and "I'm fine" are appropriate. However, similar to the cases of collocations, the student transfer the Chinese expression “我没事” character-for-character, which leads to an unidiomatic phrase "I have no matter".

2. 这可能对他们的学习生活有帮助。

This might be beneficial for their study life.

*This might be beneficial for their life and study.

While “学习生活” in this example seems to be a Chinese collocation, it should be classified as a MWU because the two words “学习” (study) and “生活” (life) are simply juxtaposed to express two separate senses rather than a sense as a whole. According to Tse (2010), an important feature of Chinese is the extensive use of parataxis at different linguistic levels. When this happens at lexical level, phrases without conjunctions will appear. However, this is not usually the case in English. When two words are to be simply juxtaposed in English, conjunctions like "and" or "or" are usually indispensable. Through retrieving the corpus, a possible appropriate expression for this Chinese MWU in English is "life and study" but not "study life".

\section{E. Patterns of and Possible Underlying Reasons for Negative Lexical Transfer}

Based on the examples discussed above, it can be summarized that the most essential pattern of negative lexical transfer is word-for-word translation. Be more specific, if the nature of polyseme transfer is to select from several possible equivalents for the source word, the mechanism of collocation and MWU transfer can be seen as the extension of this process - to choose equivalents for each word in the lexical strings.

Some possible underlying reasons for negative lexical transfer can be thereby speculated. Firstly, the complex connection between L1 and L2 may be the very reason for transfer. A number of previous studies (e.g. Cook, 2014; Jiang, 2000; Schmitt, 2000) have already pointed out that while L2 learners may become less dependent on their L1 with the increase of L2 proficiency, the process of seeking L1 words for help in using L2 lexicons will never disappear. This nature of SLA means that L2 learners are not likely to completely avoid transfer in their production of L2. Granted, transfer can be positive according to its basic framework proposed by Odlin (1989), yet this is rather unpromising since linguistic specificity varies significantly across languages (Elston-Guttler \& Williams, 2008). Moreover, for most L2 learners whose language learning is not emerged naturally from context of use (Jiang, 2000), the mastery of L2 knowledge is usually insufficient and incomplete, which might lead them to cause negative lexical transfer more easily. This feature of L2 learners is best represented by the examples of “标志建筑” (sign construction) and “学习生活” (study life), in which transfer errors were produced due to lack of English lexical resources (landmark) and unawareness of way to juxtapose words idiomatically in English (life and study).

\section{CONCLUSION AND IMPLICATION}

\section{A. Conclusion}

In spite of being a controversial issue, the existence of language transfer has already been wide acknowledged in the field of SLA. Due to the similarity and difference between learners' L1 and L2, transfer can occur either positively or negatively at various linguistic levels. At lexical level, L2 learners' production of negative transfer is an intractable problem identified in a number of previous studies (Schmitt, 2000; Jiang, 2000; Ma 2015). In Chinese context, there are few studies that collect and analyze authentic examples of L1 transfer errors caused by Chinese English learners. To fix the gap, this current research tried to identify and analyze instances of negative lexical transfer caused by Chinese polysemes, Chinese collocations, and Chinese MWUs based on the taxonomy proposed by Dodigovic et al (2015). To render the results representative of English learners of lower-intermediate proficiency, 120 pieces of writing done by students from a rural senior high school were collected, through which the learner corpus was built for further analysis. Results suggest that more than half (52\%) of the transfer errors are caused by Chinese polysemes, which are followed by Chinese collocations (29\%) and Chinese MWUs (19\%). Detailed analysis of typical examples from each category indicates misselection of possible L2 equivalents and word-for-word translation as the most pronounced patterns of lexical transfer errors. It was then inferred that the dramatic difference of lexical specificity among languages, the nature of L2 lexical processing model in SLA, and the lack of L2 knowledge could be significant underlying reasons for causing negative lexical transfer.

\section{B. Pedagogical Implications}

Some pedagogical implication for L2 lexical teaching and learning can be drawn from the results and analysis in this present study. At first, it is necessary to enrich the ways in which L2 words are taught to or learnt by students. Although 
memorizing literal definition is said to be helpful at the beginning stage of learning an L2 word (Jiang, 2004), overuse of this approach may render the influence of L1 ingrained in learners mind. To solve this problem, it will be beneficial to utilize a wider range of semantization strategies such as inferring from reading context and visual aids. The essence of these approaches is to help students learn more traits (e.g. contextual use and associated register) embedded in L2 words rather than merely literal meaning.

Subsequently, it is important for teachers to prevent students from being trapped into taking word-for-word transfer pattern for granted. As was revealed in this present study, this assumption of transfer pattern is largely responsible for negative lexical transfer. Therefore, teachers may need to make students fully aware of the infeasibility of this transfer pattern and discourage them to transfer their L1 arbitrarily into L2 without knowing the appropriate expression beforehand.

\section{Limitations and Future Research}

Although some findings have been obtained from this present study which may be pedagogically implicational, some limitations of the study cannot be ignored in terms of its methodology. Firstly, as for the learner corpus, all 120 pieces of writing were collected from merely one rural senior high school. Given the dramatic variation of educational context in different regions in mainland China, this single origin of data is far from being representative. Therefore, it is suggested that future studies should involve students from more schools in different regions to increase comprehensiveness and representativeness of results.

In addition, the analysis of transfer pattern can be another limitation. Although the taxonomy proposed by Dodigovic et al (2015) provides a rough framework for the classification of lexical transfer errors, more subtypes of negative lexical transfer can be noticed through the pattern analysis in this present study. However, due to limitation on research scale, these subtypes were only partly discussed without being systematically categorized in this study. In order to deepen the understanding of negative lexical transfer from Chinese to English, it will be necessary to focus authentic examples of lexical transfer errors yielded from each category and process further analysis.

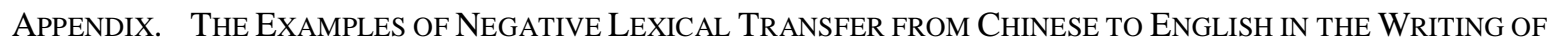 STUDENTS}

\begin{tabular}{|c|c|c|c|c|c|c|}
\hline Category & Expression as found & $\begin{array}{l}\text { Chinese } \\
\text { equivalent }\end{array}$ & $\begin{array}{l}\text { Chinese equivalent in } \\
\text { pinyin }\end{array}$ & Correct English & Context & $\begin{array}{l}\text { File } \\
\text { NO }\end{array}$ \\
\hline $\mathrm{C}$ & In the other hand & 在另一方面 & zai ling yi fang mian & on the other hand & $\begin{array}{l}\text { But in the other hand, it causes } \\
\text { dangers }\end{array}$ & 1 \\
\hline $\mathrm{P}$ & live & 住 & zhu & stay & You can live in my home & 3 \\
\hline $\mathrm{C}$ & sign construction & 标志建筑 & biao zhi xing jian zhu & landmark & $\begin{array}{l}\text { This place is full of interesting sign } \\
\text { constructions }\end{array}$ & 6 \\
\hline MWU & study life & 学习生活 & xue xi sheng huo & life and study & $\begin{array}{l}\text { This might be beneficial for their } \\
\text { study life }\end{array}$ & 13 \\
\hline $\mathrm{C}$ & solve anxiety & 解决 & jie jue & cope with & To solve anxiety, teachers need to... & 56 \\
\hline $\mathrm{P}$ & change & 兑换 & dui huan & exchange & $\begin{array}{l}\text { I found a bank and changed some } \\
\text { coins into cash }\end{array}$ & 86 \\
\hline MWU & I have no matter & 我没事 & mei shi & I'm OK & "Mom, I have no matter" & 112 \\
\hline $\mathrm{C}$ & black sky & 天黑 & tian hei & dark sky & Look! The sky is already black & 115 \\
\hline
\end{tabular}

Note: Only examples analyzed in this paper are shown in the appendix due to space constraints. If necessary, please visit http://joshua94.lofter.com/post/20588e5b_12e87098c for all 101 examples collected in the research.

\section{REFERENCES}

[1] Ädel, A., \& Erman, B. (2012). Recurrent word combinations in academic writing by native and non-native speakers of English: A lexical bundles approach, English for specific purposes, 31(2), 81-92.

[2] Biber, D., Conrad, S., \& Reppen, R. (1998). Corpus linguistics: Investigating language structure and use. Cambridge: Cambridge University Press.

[3] Biber, D. (2009). A corpus-driven approach to formulaic language in English: Multi-word patterns in speech and writing, International Journal of Corpus Linguistics, 14(3), 275-311.

[4] Carter, R. (1998). Vocabulary: Applied linguistics perspectives (2nd ed.). London: Routledge.

[5] Chen, Y. H., \& Baker, P. (2010). Lexical bundles in L1 and L2 academic writing. Language Learning \& Technology, 14(2), 30-49.

[6] Cheng, W. (2013). Semantic and Conceptual Transfer in Second Language Vocabulary Learning. A thesis in fulfilment of the requirements for the degree of Doctor of Philosophy in University of New South Wales.

[7] Clark, E. V. (2009). First language acquisition. Cambridge: Cambridge University Press.

[8] Conzett, J. (2000). Teaching collocation: Further developments in the lexical approach. Hove: Language Teaching Publications.

[9] Cook, V. (2014). How Do Different Languages Connect in Our Minds? Key Topics in Second Language Acquisition, 10(1), $1-16$. 
[10] Cook, V. \& Singleton, D. (2014). Key Topics in Second Language Acquisition. Bristol: Multilingual Matters.

[11] Dai, M. (2005). On SLA research. Foreign Language Teaching and Research, 32(2), 138-144.

[12] Dodigovic, M. (2005). Vocabulary profiling with electronic corpora: A case study in computer assisted needs analysis. Computer Assisted Language Learning, 18(5), 443-455.

[13] Dodigovic, M., Liang, H., Yue, Y. (2015). Language technology project: an application for Chinese to English machine translation post-editing and Chinese-English bilingual writing correction. Collaboration proposal.

[14] Duan, M. \& Qin, X. (2012). Collocation in English Teaching and Learning, Theory and Practice in Language Studies, 2(9), $1890-1894$

[15] Ellis, R. (2008). The study of second language acquisition. $2^{\text {nd }}$ edition. New York: Oxford University Press.

[16] Elston-Güttler, K. E., \& Williams, J. N. (2008). First language polysemy affects second language meaning interpretation: Evidence for activation of first language concepts during second language reading. Second Language Research, 24(2), 167-187.

[17] Gass, S. M. (2013). Second language acquisition: An introductory course. London: Routledge.

[18] Gass, S. M., \& Selinker, L. (1983). Language Transfer in Language Learning. Issues in Second Language Research. New York: Newbury House Publishers.

[19] Huang, C. R., Hsieh, S. K., Hong, J. F., Chen, Y. Z., Su, I. L., Chen, Y. X., \& Huang, S. W. (2010). Chinese Wordnet: Design, implementation, and application of an infrastructure for cross-lingual knowledge processing. Journal of Chinese Information Processing, 24(2), 14-23.

[20] Ijaz, I. H. (1986). Linguistic and cognitive determinants of lexical acquisition in a second language. Language learning, 36(4), 401-451.

[21] Jiang, N. (2000). Lexical representation and development in a second language, Applied linguistics, 21(1), 47-77.

[22] Jiang, N. (2004). Semantic transfer and its implications for vocabulary teaching in a second language. The modern language journal, 88(3), 416-432.

[23] Lewis, M. (1997). Implementing the lexical approach: putting theory into practice. Hove: Language Teaching Publications.

[24] Llach, M. P. A. (2011). Lexical errors and accuracy in foreign language writing. Bristol: Multilingual Matters.

[25] Lombard, R. J. (1997). Non-native speaker collocations: A corpus-driven characterization from the writing of native speakers of Mandarin (Doctoral dissertation, University of Texas at Arlington).

[26] Ma, C. (2015). Lexical Transfer from Chinese to English in the Writing of XJTLU students. Xi'an Jiaotong Liverpool University 2015 surf project report.

[27] McBride-Chang, C., Cheung, H., Chow, B. W. Y., Chow, C. S. L., \& Choi, L. (2006). Metalinguistic skills and vocabulary knowledge in Chinese (L1) and English (L2). Reading and Writing, 19(7), 695-716.

[28] Morimoto, S., \& Loewen, S. (2007). A comparison of the effects of image-schema-based instruction and translation-based instruction on the acquisition of L2 polysemous words. Language Teaching Research, 11(3), 347-372.

[29] Moon, R. (1998). Fixed expressions and idioms in English: A corpus-based approach. Oxford: Oxford University Press.

[30] Nation, I. S. (2001). Learning vocabulary in another language. Stuttgart: Ernst Klett Sprachen.

[31] Nesselhauf, N. (2005). Collocations in a learner corpus (Vol. 14). Amsterdam: John Benjamins Publishing.

[32] Odlin, T. (1989). Language transfer: Cross-linguistic influence in language learning. Cambridge: Cambridge University Press.

[33] Paquot, M. (2013). Cross-linguistic influence and formulaic language: French EFL learners' use of recurrent word sequences under scrutiny. In: Paper Presented at the Learner Corpus Research 2013, Bergen, Norway.

[34] Schmitt, N. (2000) Vocabulary in language teaching. Berlin: Ernst Klett Sprachen.

[35] Schmitt, N., \& Hemchua, S. (2006). An analysis of lexical errors in the English composition of Thai learners. Prospect: an Australian journal of TESOL, 21(3), 3-25.

[36] Shi, N. (2012). The status quo of English teaching in rural senior high school. Weekly of Examination, 90, 93-94.

[37] Sinclair, J. (1991). Corpus, concordance, collocation. Oxford: Oxford University Press.

[38] Tse, Y. K. (2010). Parataxis and hypotaxis in modern Chinese. International Journal of Arts \& Sciences, 3(16), 351-359.

[39] Wang, D. (2011). Language Transfer and the Acquisition of English Light Verb+ Noun Collocations by Chinese Learners, Chinese Journal of Applied Linguistics, 34(2), 107-125.

[40] Yamashita, J., \& Jiang, N. (2010). L1 influence on the acquisition of L2 collocations: Japanese ESL users and EFL learners acquiring English collocations, TESOL Quarterly, 44(4), 647-668.

[41] Yule, G. (2014). The study of language. Cambridge University Pres

Zhenyan Ye was born in Wenzhou, China in 1994. He received his M.A. degree in TESOL from University of Hong Kong, Hong Kong in 2017.

$\mathrm{He}$ is currently a freelance English teacher in Shanghai, providing customized courses and advice regarding curriculum development to English teaching institutions such as Education First. His research interests include second language acquisition of and language typological transfer caused by second language learners of Chinese and English. 